\title{
Concepções da atividade física: perspectivas para o fortalecimento da Nação
}

ELIAZAR JOÃO DA SILVA*

Resumo: A partir da década de 1930, e particularmente durante a Segunda Guerra Mundial, diferentes fenômenos emergiram como suposição do que seria necessário para o fortalecimento do físico da população, especialmente daquela circunscrita a países como a Alemanha e a Itália. Guardadas as proporções, verificou-se também no Brasil uma política de valorização dos esportes, sobretudo no âmbito do Estado Novo. O artigo analisa esta questão.

Abstract: From the 1930's, particularly during World War II, some different phenomena rise as alternatives to strengthen the people's physical, especially in countries like Germany and Italy. Keeping different proportions, that phenomenon was seen in Brazil through a policy to increase the value of the physical activities, mainly during the Estado Novo. This article tries to analyze that policy.

Palavras-chave: Nação. Educação Física. Política.

Key words: Nation. Physical Education. Politics.

A implantação do regime republicano no Brasil foi um fenômeno caracterizado por perspectivas de transformações que visavam, entre outras coisas, romper com a estrutura anteriormente verificada nos âmbitos sociais e políticos do país. Constatou-se-se, na prática, que vários dos projetos anunciados não corresponderam com o discurso republicano, na medida em que não se conviveu com a plenitude da cidadania quanto aos direitos civis, políticos e sociais. Do ponto de vista político (para apenas indicar um aspecto), mais da metade da população não podia expressar sua vontade nas urnas por ocasião da votação para Presidente da República. ${ }^{1}$

* Professor de História da Universidade Federal da Grande Dourados - UFGD -, Mato Grosso do Sul. Doutor em História pela UNESP/Campus de Assis.

E-mail: eliazarsilva@hotmail.com

Estudos Ibero-Americanos. PUCRS, v. XXXIII, n. 2, p. 172-187, dezembro 2007 
Uma questão, entretanto, chamou particularmente a atenção no final do século XIX. Trata-se de um processo que se intensificou apontando para a construção da nacionalidade. Para tanto, diferentes instrumentos foram explorados para esta construção. A prática de esportes notabilizou-se quanto a esta possibilidade, em especial, a atividade futebolística.

De esporte inicialmente praticado preponderantemente pelas camadas sociais mais abastadas, rapidamente o futebol passou a ser praticado também pelas camadas sociais menos favorecidas economicamente. ${ }^{2}$ A partir do momento em que ele se transformou num fenômeno popular, o futebol foi amplamente explorado pelo governo federal como um dos símbolos da nacionalidade. Um dos objetivos de representantes do governo foi o de se propagar uma idéia de que a prática de esportes levaria à construção de um homem novo, ${ }^{3}$ preparado para os desafios do futuro da Nação. Pretende-se, neste artigo, analisar este processo.

Várias legislações emergiram no país a partir da década de 1930. Dentre elas, algumas diziam respeito à prática dos esportes, ${ }^{4}$ justamente como decorrência do seu alcance popular, sobretudo o futebol. Diferentes personalidades tornaram-se importantes na execução de um projeto estratégico que visava a construção do homem novo. Neste aspecto, destacavam-se especialmente educadores, médicos, sanitaristas, dirigentes esportivos, eugenistas e higienistas.

Havia uma convergência para o ideal do civismo, da moral, da boa performance do físico e do sentimento patriótico. Estes elementos eram tidos como preponderantes para o discurso oficial ligado ao Brasil "forte e saudável". A juventude brasileira deveria estar preparada para este novo cenário. ${ }^{5}$ Tornava-se premente a necessidade de se explorar as diferentes possibilidades que pudessem garantir uma boa saúde para a população.

A este respeito, ver, entre outros, CARVALHO, José Murilo de. Os bestializados: o Rio de Janeiro e a República que não foi. São Paulo: Companhia das Letras, 1987.

2 Cf. SILVA, Eliazar João da. Bola na rede - o futebol em São Paulo e no Rio de Janeiro: do amadorismo à profissionalização. Assis: UNESP/Dissertação de Mestrado, 2000.

3 Cf. GOMES, Ângela de Castro. História e historiadores: a política cultural do Estado Novo. Rio de Janeiro: FGV, 1999.

4 Cf. PERRY, Valed. Futebol e legislação. Rio de Janeiro: Vitória, 1973.

5 Ver entre outros, os trabalhos de BERCITO, Sônia de Deus Rodrigues. Ser forte para fazer a nação forte: a educação física no Brasil (1932-1945). São Paulo: USP/Dissertação de Mestrado, 1991. MARINHO, Inezil Pena. História da educação física e dos desportos no Brasil: Brasil Colônia, Brasil império, Brasil República (documentário e bibliografia). Rio de Janeiro: DEF-MES, 1952, vol. 4. 
A atividade esportiva, desse modo, seria um dos elementos que deveria - na perspectiva de representantes do poder público se prestar também a estes objetivos. Não por acaso, a crescente popularidade e o interesse pelo futebol foram amplamente motivados pelo governo federal, não somente nesta década de 1930, mas também no período posterior. Vários esforços foram empreendidos, por exemplo, para que a Copa do Mundo de 1950 se realizasse no Brasil.

A partir da efetiva condição do país sediar o mais importante campeonato internacional do futebol, dois imponentes centros esportivos foram erguidos contando-se com dinheiro público. Trata-se do Pacaembu (localizado na cidade de São Paulo) e do Maracanã (localizado na então capital federal). A institucionalização da educação física ocorreu justamente durante o Estado Novo, embora nas décadas anteriores ela já merecesse especial atenção por parte do poder público, ${ }^{6}$ o que indica a dimensão que se atribuia à prática de esportes.

A concepção da educação física, nesse período, foi importante para que se entendessem as "funções" dos esportes nos anos seguintes. Consideramos elucidativa a afirmativa de Mazzoni sobre esta questão. Para ele, "a força de uma nação é o complexo da força física, intelectual e moral de cada um de seus elementos. É a resultante das forças resultantes que a compõem". ${ }^{7}$

Uma das propostas do governo federal, consistiu na idéia de que a educação física deveria ajustar-se à doutrina do Estado Novo. O próprio autor mencionado produziu seus textos, neste período, a partir da discussão acerca dos interesses do governo federal em relação à prática esportiva.

O Brasil precisa de homens inteligentes e disciplinados: - deve cuidar, portanto, de tornar sadia e forte sua mocidade. Em todos os países do mundo civilizado, o esporte tem merecido dos governos a máxima atenção $[\ldots] \cdot{ }^{8}$

Segundo Alcir Lenharo, o cuidado com o corpo simbolizava um dos significados da prática esportiva no país deste período. Nesta perspectiva, os ideólogos do Estado Novo buscavam "a moralização do corpo pelo exercício físico; o aprimoramento eugênico incorporado à raça; a ação do Estado sobre o preparo físico e suas

6 Cf. FILHO, Mário Ribeiro Cantarino. A educação física no Estado Novo: história e doutrina. Brasília: UNB/Dissertação de Mestrado, 1982.

7 Cf. MAZZONI, Thomaz. O esporte a serviço da pátria. São Paulo: Olympicus, 1945, p. 7.

8 Cf. MAZZONI, op. cit., p. 32. 
repercussões no mundo do trabalho". ${ }^{9}$ Tais suposições apresentadas por Lenharo, demonstravam quais seriam os aspectos que norteariam a exploração dos esportes pelo Estado Novo.

A condição de se valorizar os esportes como "atividade necessária" para se manter um físico saudável, buscando-se preparálo também para eventuais conflitos internacionais, foi uma realidade na Europa do final do século XIX. Entretanto, ainda em meados da década de 1910, sobretudo após a primeira guerra mundial, a educação física foi objeto de especial interesse por parte do governo federal.

No tocante à concepção das atividades físicas durante e após os conflitos internacionais, Sevcenko afirmou que "nesse contexto é que as atividades atléticas tiveram o seu boom, compreendidas como um segredo militar para a adequada preparação das tropas em vista das condições de combate".10

Foi no final do século XIX que se verificaram as primeiras formas de praticar o esporte de modo minimamente organizado no Brasil. De maneira intensa, ele era praticado em colégios, nos quais se convivia com a presença de vários alunos, filhos de imigrantes europeus.

Antevendo os benefícios que a educação física poderia proporcionar à sociedade, Anatol Rosenfeld disse que "seu triunfo está estreitamente ligado, também à Europa, à industrialização e ao surgimento das grandes cidades. [...]. Onde faltou a iniciativa do Estado, entrou em ação o impulso dos imigrantes". ${ }^{11} \mathrm{O}$ "impulso" ao qual Rosenfeld faz referência deve ser creditado aos vários brasileiros que, após retornar de períodos de estudos na Europa, também foram protagonistas quanto à propagação das atividades esportivas, sobretudo em meio às camadas sociais mais abastadas.

Entretanto, na medida em que as décadas avançavam, a atividade esportiva foi absorvida pelas diferentes camadas sociais, não apenas como um elemento que proporcionava lazer e integra-

9 LENHARO, Alcir. Sacralização da política. Campinas: Papirus, 1986, p. 77-78.

10 SEVCENKO, Nicolau. Futebol, metrópole e desatino. Revista USP - Dossiê futebol, São Paulo, n. 22. 1994, p. 33. Sobre esta temática, ver também de Sevcenko, Nicolau. Orfeu extático na metrópole. São Paulo, sociedade e cultura nos frementes anos 20. São Paulo: Companhia das Letras, 1992. Cf. especialmente o capítulo 1: "A abertura em acordes heróicos dos anos loucos” (p. 23-88). A guerra à qual Sevcenko faz referência foi a ocorrida entre 1914-1918.

11 ROSENFELD, Anatol. Negro, macumba e futebol: São Paulo: Perspectiva, 1993, p. 76. Sobre a absorção do futebol nos grandes centros urbanos, ver também SILVA, Eliazar João da. Bola na rede - O futebol em São Paulo e no Rio de Janeiro: do amadorismo à profissionalização. Assis: UNESP/Dissertação de Mestrado, 2000, p. 47-91 
ção entre as pessoas, mas, sobretudo, porque seria um instrumento pertinente ao exercício de "educação e de dinamismo".

Fernando de Azevedo foi um dos principais estudiosos da trajetória da atividade esportiva no Brasil da primeira metade do século XX. Especificamente sobre o futebol, ele afirmou que "a juventude parece ter tido a intuição de que este esporte era o mais completo do ponto de vista educativo e psicodinâmico, e por isso recebeu-o de braços e corações abertos como se tivesse esperado por ele desde há muito tempo". ${ }^{12}$ Contudo, além do caráter educacional (conforme Azevedo chamou a atenção), o esporte adquiriu outros tantos significados.

Um dos aspectos da valorização da educação física residia na condição de se conferir aos esportes um importante instrumento para a construção de um projeto de eugenia da sociedade. ${ }^{13}$ Além de autores como Azevedo, tal proposição contava com outros adeptos, dentre os quais, profissionais da educação, da medicina e do direito. Em 1918, foi fundado em São Paulo, o "Instituto Brasileiro de Eugenia". O médico Renato Ferraz Kehl dirigiu esta instituição até 1929. Em vários países da Europa, existiam associações, cujos objetivos vinculavam-se aos projetos de "fortalecimento" da população. Na Inglaterra, por exemplo, existia uma associação fundada em 1907, cujo diretor foi Leonardo Darwin, filho de Charles Darwin. ${ }^{14}$ A estrutura da educação física no Brasil teve inspiração no modelo europeu, em especial no francês e inglês..$^{15}$

No intervalo entre a Primeira e a Segunda Guerras Mundiais, a atividade esportiva adquiriu maior importância no cenário internacional. A associação do esporte com as transformações que vinham acontecendo, foram imediatamente analisadas por alguns autores. Atrelou-se também à recepção das atividades esportivas, fenômenos como os da militarização, da remodelação dos centros

12 AZEVEDO, Fernando de. A evolução dos esportes no Brasil (1822-1922). São Paulo: Melhoramentos, 1953, p. 31.

13 Cf. AZEVEDO, Fernando de. A poesia do corpo. Belo Horizonte: Imprensa oficial do Estado de Minas Gerais, 1915. Este trabalho é resultado de uma tese apresentada ao concurso à vaga de professor da cadeira de ginástica e educação física do ginásio mineiro. Em 1922, a tese apresentada por Azevedo foi ampliada, e se transformou em livro intitulado Da Educação Física, publicado pela editora José Olympio.

14 A esse respeito, ver os trabalhos de BIZZO, Nélio Vicenzo. O paradoxo social eugênico, genes e ética. Revista USP: Dossiê gênero e ética, São Paulo, n. 24, 1994-1995, p. 28-37. KEHL, Renato Ferraz. A eugenia no Brasil. In: Congresso Brasileiro de Eugenia. Rio de Janeiro: s/e, 1929, p. 45-62. MARQUES, Vera Regina Beltrão. A medicalização da raça: médicos, educadores e discurso eugênico. Campinas: Ed. da UNICAMP, 1994.

15 Cf. MARINHO, op. cit. 
urbanos, dos progressos científicos e tecnológicos. Segundo Sevcenko,

Não apenas em função das exigências do ritmo de produção cadenciado pelas máquinas e de situações de emergência como as guerras ou grandes evacuações, é que as autoridades desde cedo começaram a investir pesado em educação física, atletismo, esportes de disciplina coletiva. Há aí até um sútil jogo de polarizações, dado que, uma vez postas as condições tecnológicas que exigiam uma automoção das reações físicas e reflexos humanos, houve uma tendência adaptativa no sentido de buscar um novo condicionamento corporal partindo da própria população, que se predispôs a uma intensificação e diversificação de seus dispêndios físicos, os quais em muitos casos só ulteriormente foram direcionados e formalizados em termos institucionais pelas autoridades ou pela nascente indústria das diversões e entretenimentos baratos. ${ }^{16}$

O ideal que visava a militarização da juventude, tendo a educação física como um dos elementos de sua afirmação, é singular no processo de implantação institucional das atividades esportivas em meio ao serviço militar. Em 1908, iniciou-se uma campanha pela lei do serviço militar obrigatório, apoiada por Olavo Bilac, poeta e filho de militares. Ele tinha a simpatia de vários setores da sociedade brasileira, razão pela qual, Bilac foi importante neste movimento. Na década seguinte, tal campanha obteve maiores dimensões, estimulada, especialmente, pela eclosão da Primeira Guerra Mundial, ${ }^{17}$ conforme mencionado anteriormente.

Além de Bilac, outras personalidades da literatura brasileira manifestaram, em vários momentos, seu apoio às práticas esportivas, com exceção de alguns críticos, e que se opunham a algumas destas práticas, como o futebol. Lima Barreto e Graciliano Ramos, por exemplo, estão entre aqueles que, invariavelmente, escreviam sobre os "males" que o futebol poderia ocasionar à sociedade brasileira, sobretudo aos negros e aos mais pobres. ${ }^{18}$ Contudo, existiam outros tantos que difundiam os "benefícios" da atividade física, dentre os quais, Olavo Bilac e Coelho Neto.

Está fora de dúvida que as finais inteligências, quer se apliquem às mais requintadas expressões artísticas, quer se dediquem aos grandes surtos literários sempre encontraram nas formas superiores do

16 SEVCENKO, Nicolau. Futebol, metrópole e desatino. Revista USP: Dossiê Futebol. São Paulo, n. 22, 1994, p. 34.

17 Sobre o serviço militar obrigatório, ver HORTA, José Silvério Baia. O hino, o sermão e a ordem do dia: regime autoritário e a educação no Brasil. Rio de Janeiro: Ed. UFRJ, 1994.

18 Cf. SILVA, op. cit., p. 122-173. 
esporte motivos dos mais abundantes e sugestivos para inspiração de alguns dos seus melhores lavores. Conhece-se bem, por exemplo, o decidido pendor que o festejado literato Coelho Neto tem por tudo que diz respeito ao esporte, do qual vem sendo, há muitos anos, um dos mais brilhantes paladinos. Poucos hão de conhecer, porém, a brilhante página que os jogos olímpicos da época clássica, quando a Grécia era realmente grande tanto em pensamentos como em ação, inspiraram a Olavo Bilac, o saudoso príncipe dos poetas brasileiros. Esta página é a seguinte: "Jogos Olímpicos [...] é impossível escrever ou ler essas duas palavras sem evocar a idade de ouro da humanidade, no berço daquela Grécia divina, cuja misteriosa e indizível saudade arde perpétua, por um milagre físico na alma de todo homem que pensa. Tal é o prestígio da Helade antiga, que cada um de nós, fechando os olhos, vê reproduzirem-se todo o cenário, toda a gente, toda a história, todos os costumes dessa remotíssima idade. É que cada um de nós, artistas e poetas, sempre tem dentro da própria alma um pouco da gente de Peloponeso. ${ }^{19}$

É tenaz a relação entre educação física e serviço militar, entendido também como um instrumento de "defesa nacional". A idéia era a de que se deveria preparar os jovens para eventuais conflitos internacionais, e para tanto, a juventude deveria ser fisicamente forte. A possibilidade da implementação dos cursos de educação física obteve mais importância justamente nesse contexto. Tal compreensão, todavia, esteve presente, fundamentalmente, em países como a Itália e a Alemanha. ${ }^{20}$

A perspectiva da militarização dos esportes e da própria juventude foi diretamente influenciada pela Europa. O modelo de associação da educação física com o serviço militar brasileiro, guarda similaridades em relação ao modelo francês, cujas características remeteriam ao que se verificava nas funções da educação física em cidades como as de Paris. "No Brasil, já em 1921 foi aprovado o regulamento de Instrução Física Militar, destinado ao Exército e calcado no projet francês, por influência direta da Missão Militar Francesa, recentemente chegada ao Brasil". ${ }^{21}$ Embora tal centro militar não chegasse a ser instalado em 1922 (conforme se previa), a associação da educação física militar a partir de uma orientação francesa, norteou as práticas esportivas estabelecidas pelo exército.

19 O que diz o grande Bilac dos jogos olímpicos. O Estado de São Paulo, 24-01-29.

20 SOARES, Carmen. Educação Física: raízes européias e Brasil. Campinas: Autores Associados, 1994.

21 Cf. CASTRO, Celso. In corpore sano - os militares e a introdução da educação física no Brasil. Revista Antropolítica, Niterói, n. 2, 1997, p. 5. 
Ao final da década de 1920, o General Nestor Sezefredo Passos (Ministro da Guerra) assinou uma portaria (prevista para 1922), em 11 de janeiro de 1929, que consistiu na organização do Centro Militar de Educação Física. Um dos aspectos desta portaria, dizia respeito à obrigatoriedade do ensino de educação física para homens e mulheres, a partir dos seis anos de idade, em todos os estabelecimentos de ensino do país, quer fossem públicos ou particulares. ${ }^{22}$

A direção das escolas, bem como o conjunto de professores dos colégios receberam, de modo relativamente irrestrito, a idéia da implantação e da "necessidade" da educação física nos estabelecimentos de ensino e em outros espaços sociais. A imprensa não esteve alheia a este processo. Jornais de grande circulação nesse período acompanharam esse movimento. Foi o caso de $O$ Estado de São Paulo, ao valorizar em suas notícias diárias, os benefícios da educação física, conforme citação a seguir:

Para o adestramento da criança, é preciso estabelecer-se que, todos os que educam os meninos: professores, preceptores, mestres de escola, instrutores de ginástica e de jogos e exercícios físicos, estejam compenetrados da sua alta missão e inspirados no mesmo espírito levantado. Com tal objetivo, é forçoso que, cada país, na medida do possível se fundem uma ou algumas escolas esportivas, nas quais possam os alunos não só aperfeiçoar a técnica dos diversos esportes, como sobretudo, a moral que a deve inspirar. [...]. A comissão [Olímpica Internacional] desejaria que fosse declarada obrigatória a frequência às escolas citadas, por período de duração mais ou menos longa, conforme a necessidade, para todos os que desejassem, de qualquer forma, ocupar-se da educação infantil. [...]. Assim, criarse-ia em todo o magistério uma atmosfera de veracidade, de camaradagem e de espírito esportivo, cuja influência produziria, pouco a pouco, inclusive entre os meninos, uma opinião pública, que condenaria todos os quantos se afastassem dos princípios esportivos e imporia a lealdade, a honra e o respeito ao próximo. [...]. Para a educação esportiva do adulto, conviria que os diversos clubes elegessem para diretores de esporte elementos que se hajam preparados em semelhante escola. A comissão está convencida de que, para alcançar tais resultados, será necessário muito tempo e o emprego de muita boa vontade; mas tenho a certeza de que, para a maior parte dos povos, este é o único meio capaz de difundir e generalizar o espírito esportivo. ${ }^{23}$

22 Cf. CASTELLANI FILHO, Lino. Educação física no Brasil: a história que não se conta. Campinas: Papirus, 1991, p. 130-146.

23 Educação esportiva. O Esatdo de São Paulo, 10-01-29. 
Sob a orientação do primeiro-tenente Inácio de Freitas Rolim, as atividades iniciais do Centro Militar de Educação Física ocorreram nas dependências da Escola de Sargentos de Infantaria da Vila Militar no Rio de Janeiro. Em período posterior a 1930, tal centro estabeleceu-se na Fortaleza de São João, também no Rio de Janeiro. O curso tinha como objetivo precípuo, preparar profissionais para lecionar educação física.

Além de militares, civis tornaram-se também professores, os quais lecionavam em escolas públicas e privadas. Difundia-se pelas principais cidades mais populosas do país, no ano de 1929, a idéia da necessidade de busca do físico saudável, utilizando-se também os cursos de educação física, oferecidos pelas escolas. Iniciaram-se, inclusive, vários eventos relacionados à atividade esportiva.

A comissão de ensino particular, que é encarregada de conseguir a adesão dos colégios particulares à semana da Cultura Física, apresentou aos representantes destes estabelecimentos de ensino o seguinte programa: Desfile, no local previamente indicado de todas entidades educativas que houverem aderido ao programa. Usará cada uma o uniforme que deliberar, e será acompanhada do respectivo professor de ginástica; execução de pequeno programa de ginástica coletiva racional, ou segundo o método que o professor houver adaptado para o ensino. [...]. Haverá alguns exercícios com aparelho racional, que oportunamente se escolherá, efetivados por turmas de alunos dos colégios que aderirem. [...]. A comissão de ensino particular, segundo nos comunica, deseja que nesta competição tomem parte os alunos de ambos os sexos. Já aderiram à demonstração os seguintes estabelecimentos: Colégio Stanfford, Colégio Pedro II, Colégio Mackenzie, Instituto Dante Alighieri e Liceu FrancoBrasileiro. $^{24}$

Parte da imprensa (como o jornal O Estado de São Paulo, por exemplo) concebia o sentido para o qual os esportes deveriam ser praticados, avalizando a perspectiva do governo federal. Nas matérias publicadas, havia não somente uma condição de se noticiar os aspectos inerentes à educação física, mas sobretudo um incentivo e uma divulgação dos supostos benefícios da prática dos esportes.

Não é de hoje que temos simpatia pelos esportes escolares. Já nos batemos, por várias vezes, pela organização de campeonatos entre alunos dos colégios secundários e das faculdades. A nossa campanha, embora não tivesse sido insistente, se não calou fundo em todos os estabelecimentos de ensino, todavia encheu de coragem vá-

24 A semana de cultura física. O Esatdo de São Paulo, 16-04-29. 
rios abnegados, que se dedicam com afinco para a preparação, mais lógica e mais regular, dos futuros expoentes do esporte..$^{25}$

A partir da idéia de que vários dos periódicos eram afinados aos propósitos do que o governo federal deliberasse, veículos de comunicação tiveram, mais uma vez, um papel importante quanto à divulgação dos "benefícios" da educação física. Ademais, a perspectiva de que a atividade esportiva significava uma "boa saúde", teve o apoio de diferentes segmentos sociais, em especial, dos órgãos institucionais, e estabelecimentos de ensino. Neste sentido, as escolas foram espaços privilegiados para a difusão da importância da educação física. Segundo Maria Helena Capelato,

No Brasil da década de 20, a escola foi idealizada, acima de tudo, como lugar de definição da ordem. [...]. Renovar o ensino significava renovar a sociedade dentro da ordem. E foi com esse objetivo que jornalistas e educadores lançaram-se na campanha pela reformulação educacional. O OESP tomou a iniciativa de abrir amplo debate sobre o tema: a idéia de promover um inquérito sobre a instrução pública de São Paulo partiu de Júlio de Mesquita Filho, que encarregou Fernando de Azevedo, membro da equipe de redação do periódico, de realizá-lo. ${ }^{26}$

A educação física, e por extensão as atividades esportivas, se tornariam efetivas e institucionalmente um pressuposto básico da garantia de lazer, do físico saudável, e da própria educação. Durante a década de 1930, ela significaria o "corpo da Nação", com o acompanhamento e intervenção do Estado. "Governo forte, relações sociais disciplinadas, indústria: estão dadas as condições da gestação de um novo tempo". ${ }^{27}$ Cremos que, para além dos benefícios anunciados pelo poder público (os quais a sociedade deveria usufruir), estava subjacente a idéia da construção de um projeto de eugenia do povo brasileiro, via atividade esportiva. ${ }^{28}$

25 O esporte nas escolas. O Estado de São Paulo, 23-10-29.

26 Cf. CAPELATO, Maria Helena. Os arautos do liberalismo - imprensa paulista: 19201945. São Paulo: Brasiliense, 1989, p. 147-148. Vale observar que embora houvesse um grande número de periódicos afinados às medidas adotadas pelo governo, havia outros tantos que a ele se opunham.

27 Cf. LENHARO, Alcir. Sacralização da política. Campinas: Papirus, 1986, p. 67.

28 Segundo Lenharo, "o avanço na produção de corpos fortes e dóceis, esteio da 'higiene da raça', requeria uma política repressiva e preventiva para a salvaguarda do 'patrimônio hereditário"” (LENHARO, op. cit., p. 79). São relativamente numerosos os trabalhos que investigam o projeto de eugenia e fortalecimento da "raça" brasileira, utilizando-se o esporte para a execução desse projeto. Vale menção aqui, um importante trabalho de Mestrado, defendido na UFMG em 1999 por PEREIRA, Júlia Sales. A escultura da raça: juventude e eugenia no Estado Novo. Belo Horizonte: Dissertação de Mestrado/UFMG, 1999. 
Desde o final do século XIX, as teses que justificavam o projeto da eugenia continuavam presentes, embora tenha sido no âmbito do Estado Novo que tal idéia obteve maiores contornos. Foi nesse período que se perseguiu, de forma objetiva, a construção do "homem novo", cujo espírito da nacionalidade, e da valorização do trabalho como um dever moral, constituíam alguns de seus pressupostos básicos. O discurso do Estado remetia a uma ampla associação do "corpo forte" significando um "Brasil forte". ${ }^{29}$

Essa construção do homem novo foi fundamental para o projeto do progresso do Brasil nas suas diferentes perspectivas. Gustavo Capanema, então Ministro da Educação, apresentava um discurso durante o Estado Novo no qual havia uma indicação de que o processo educacional tinha o papel de controle social e disciplinarização de crianças e adolescentes do Brasil. ${ }^{30}$

Deste modo, a escola seria o espaço ideal de diálogo entre a família e a sociedade. Nessa perspectiva, o exército e a educação física tinham papel significativo quanto à absorção desse ideal, e, sobretudo, de legitimidade das ideologias anunciadas por esse Estado.

As forças armadas, numa demonstração vibrante de brasilidade, pelas suas figuras de maior prestígio nos meios do esporte, estão empenhadas num magnífico trabalho de desenvolvimento do esporte base. Objetivando o aprimoramento eugênico dos soldados nacionais, tanto o exército quanto a marinha, pelas suas entidades especializadas, cuidam, com interesse, da difusão do atletismo. [...]. Integrando-se nesse surto de entusiasmo, $A$ Noite orgulha-se de ver, mais cedo do que era de esperar, correspondidos os seus esforços no sentido de aprimoramento racial. ${ }^{31}$

O fortalecimento da "raça brasileira", associado ao ideal da valorização da atividade esportiva durante o Estado Novo, caracterizaram a orientação do poder público com vistas à construção do chamado "homem novo": trabalhador consciente do sentimento do patriotismo, educado de acordo com as novas propostas pedagógicas que legitimavam o Estado, receptivo e apto às perspectivas da eugenia como sentido da "grandeza da Nação".

Estes pressupostos - dentre outros - também foram importantes para a representação do futebol como símbolo de identidade nacional. Este processo alcançou seu auge na realização da copa do

29 A esse respeito ver BERCITO, Sônia de Deus Rodrigues. Ser forte para fazer a nação forte: a educação física no Brasil (1932-1945). São Paulo: Dissertação de Mestrado/USP, 1991.

30 Cf. SCWARTZMAN, Simon (org.). Tempos de Capanema São Paulo: Paz e Terra, 1984.

31 Soldados fortes: belos soldados do Brasil. A Noite, 19-01-37. 
mundo de 1950 no Brasil, ${ }^{32}$ ocasião em que se verificou uma efetiva movimentação em torno dos jogos da seleção brasileira, como momentos em que se experimentaram situações de "orgulho nacional", através das vitórias da equipe brasileira.

Em pesquisa realizada sobre a educação física no Brasil, Carmem Lúcia Soares apresenta um texto no qual a prática esportiva e por extensão a educação física - impõem-se como instrumentos a serem explorados pelo Estado na busca desse homem novo. Segundo Soares: "No caso do Brasil, a educação física aparecerá colada aos ideais eugênicos de regeneração e embranquecimento da raça, figurando em congressos médicos, em propostas pedagógicas e em discursos parlamentares". 33 A educação física levaria, desta maneira, ao ideal da regeneração com a negação do ócio, da preguiça, da indolência, entraves à "ordem e ao progresso" do Brasil.

Verifica-se, deste modo, a idéia de que, para um país supostamente "civilizado e educado", seu governo haveria de implementar políticas que condenassem comportamentos sociais considerados "negativos". Para tanto, dever-se-ia buscar o fortalecimento do físico e da valorização do trabalho. ${ }^{34}$

O Estado se encarregaria de desenvolver novas formas de controle ideológico. A extensão da escolarização primária, assim como dos serviços de saúde, representariam duas importantes formas de controle ideológico inovadas pelo Estado. [...]. É elaborado mais uma forma de intervenção na realidade social, a qual operará tanto em nível corporal dos indivíduos isoladamente, quanto ao nível do "corpo social", quando tornada hábito. Estamos nos referindo à educação física, que já no século XIX chega aos foros científicos com seu conteúdo médico-higiênico e com sua forma disciplinar voltada ao "corpo biológico". [...]. Os médicos higienistas, imbuídos da certeza que detinham uma maior competência para redefinir os "hábitos" da família moderna, não poderiam ter deixado de influenciar de maneira decisiva o referencial de conhecimentos necessários para o desenvolvimento da educação física, um mecanismo a mais utilizado na construção do homem novo. ${ }^{35}$

O "desenvolvimento e o progresso" da Nação passavam, necessariamente, pela difusão de elementos propagados pelo Estado Novo. Tais elementos estavam baseados numa "cultura política"

32 Cf. SILVA, Eliazar João da. A Taça do mundo é nossa! O futebol como representação da nacionalidade. Governador Valadares: Ed. Univale, 2006.

33 Ver SOARES, Carmem Lúcia. Educação física: raizes européias e o Brasil. Campinas: Autores Associados, 1994, p. 25

34 Cf. GOMES, op. cit.

35 SOARES, op. cit., p. 41-42. 
encaminhada oficialmente pelos ideólogos do regime. ${ }^{36}$ Para estes, o Estado deveria intervir na prática de esportes como efetiva perspectiva de garantia da melhoria da saúde da população.

O Departamento de Imprensa e Propaganda, encarregava-se do processo de divulgação e de legitimidade do novo regime, cujo objetivo precípuo seria o de enaltecimento da imagem do governo, ${ }^{37}$ através também da exploração de diferentes manifestações da cultura popular, entre elas, o futebol e a música. ${ }^{38}$

Não obstante o sentido da compreensão da importância do DIP quanto à propaganda política do Estado Novo, ele não pode, essencialmente, ser caracterizado de forma semelhante ao que foi feito em países como a Alemanha e a Itália, ${ }^{39}$ cujos meios de comunicação eram mais incisivos quanto à exploração do esporte, por exemplo. Consideramos, todavia, que várias de suas publicações remetiam à legitimidade do governo, como foi o caso das atividades esportivas através da coletânea de textos produzidos no Estudos e Conferências. ${ }^{40}$

De todo modo, o DIP teve papel destacado nesse período. A radiodifusão e a imprensa escrita tinham o seu direto acompanhamento. Tanto um quanto outro, veículo de informação comportavam-se de acordo com o entendimento das orientações deste departamento. A revista Cultura política foi uma das mais importantes publicações oficiais do Estado Novo.

36 Em trabalho sobre esta perspectiva do Estado Novo, ver OLIVEIRA, Lúcia Lippi (org.). Estado Novo: ideologia e poder. Rio de Janeiro: Zahar Editores, 1982. Cf. especialmente os capítulos III e V, denominados, respectivamente, "Cultura e poder político" e "A construção do homem novo". Entre os ideólogos do Estado Novo, destacam-se Azevedo Amaral e Almir de Andrade. Sobre esta questão ver também GOMES, Ângela de Castro. História e historiadores: a política cultural do Estado Novo. Rio de Janeiro: FGV, 1999

37 Dentre os trabalhos já citados que discutiram a questão da propaganda política do Estado Novo, tendo-se o DIP como órgão oficial incumbido de organizar esse processo, mencione-se, GARCIA, Nelson Jahar. Estado Novo, ideologia e propaganda política. São Paulo: Loyola, 1982. GOULART, Silvana. Sob a verdade oficial: ideologia, propaganda e censura no Estado Novo. São Paulo: Marco Zero, 1990. Fazendo um levantamento sobre os trabalhos produzidos sobre a ideologia política do Estado Novo, ver CAPELATO, Maria Helena. Estado Novo: novas histórias. In: Historiografia brasileira em perspectiva. São Paulo: Contexto, 2001, p. 183-213.

38 Villa Lobos, um dos mais importantes músicos do século XX, compôs várias canções, cujas letras enalteciam o regime do Estado Novo. Segundo Garcia, Villa Lobos aproximava os cantores e as canções populares à ideologia política do governo Vargas (GARCIA, op. cit., p. 109).

39 CAPELATO, op. cit., p. 212-213.

40 Cf. Estudos e Conferências, Rio de Janeiro: DIP, n. 14. 1941. Nesta coletânea, encontram-se artigos discutindo a importância do esporte como elemento de "fortalecimento do povo brasileiro". 
Um dos objetivos de Cultura política foi o de justamente propagar e registrar as "realizações" do governo quanto aos aspectos políticos, econômicos e culturais. Personalidades como Francisco Campos e o próprio Lourival Fontes, diretor do DIP, e ex-chefe da delegação brasileira de futebol, que disputou a Copa do Mundo da França em 1938, dentre outros, colaboravam com artigos na mencionada revista. ${ }^{4}$

De um lado os teóricos da educação física demonstram clara e objetivamente a "não homogeneidade do nosso povo brasileiro", argumentando [...] que somente será realizado o "milagre integral do homem brasileiro" com a "preparação cultural das elites" e "formação eugênica das massas", de outro os ideólogos do Estado Novo, que escrevem na Cultura Política, tentam argumentar aparentemente o contrário, ou seja, que apesar de sermos "raça de mestiços", com a "inteligência, a atrocidade e a avidez do branco", com a "servilidade do preto" e a "altivez indômita do íncola", argamassas do cadinho psicológico do jesuíta, possuímos uma nacionalidade brasileira. ${ }^{42}$

A partir das interpretações de Lima, verifica-se a busca da homogeneidade racial marcada por rótulos do etnocentrismo, caracterizados em interpretações sobre o país. De outro lado, procura-se justificar a heterogeneidade racial através da miscibilidade racial, da qual é formada a sociedade brasileira. Entretanto, percebe-se nesses discursos, a idéia da formação e a construção do homem brasileiro.

Várias das leituras e interpretações que foram feitas acerca da formação do Brasil (paralelamente à construção do ideal do homem trabalhador, sadio e forte), foram utilizadas pelo poder público, o qual intervinha diretamente nos elementos culturais propagados pelo DIP. Era necessário que se conhecesse e que se reconhecesse a trajetória da formação da Nação. Nesse sentido, não somente a educação física, mas outros elementos manifestados no cotidiano como as canções populares deveriam ser fiscalizadas pelo Estado.

O esforço educativo do Estado Nacional ultrapassava as fronteiras do ensino sistemático, engajando-se em uma dimensão cultural de valorização e de preocupação com a arte nacional. [...]. A atuação do

${ }^{41}$ Cf. OLIVEIRA, op. cit., p. 71-104. Sobre esta questão, ver o importante texto de GOMES, op. cit. Nesse trabalho, a autora analisou minuciosamente as publicações da revista Cultura política, em especial a partir do capítulo 4: "O Estado Novo e a recuperação do passado brasileiro" (p. 125-210).

42 Cf. LIMA, Magali Alonso. Formas arquiteturais esportivas no estado Novo (1937-1945): suas implicações na plástica de corpos e espíritos. Rio de Janeiro: Funarte, 1979, p. 35. 
Estado para com a arte e particularmente com a arte popular destacava-se, por exemplo, no reconhecimento do valor e do "poder de sugestão" da música popular. E os efeitos da nova política social já podiam ser sentidos em um grande número de composições. [...]. O rádio e a música popular eram, desta forma, instrumentos valiosos de propaganda e doutrinação políticas. Além do programa A Hora do Brasil, o DIP tinha um controle absoluto sobre tudo o que se relacionava a música popular. ${ }^{43}$

Conforme se verifica, o poder público, através de órgãos oficiais como o DIP, foi construindo, a partir da década de 1930, o sentido de símbolos da identidade nacional conferido também às atividades esportivas, especialmente ao futebol. Nas décadas seguintes, esse processo atingiu seu ápice, sobretudo na década de 1950, após a conquista da primeira copa do mundo em 1958, realizado na Suécia. ${ }^{44}$ Foi justamente neste campeonato que surgiu "Pelé", considerado o principal futebolista do século XX.

Diante de eventos concebidos como "nacionais" através, por exemplo, das participações da seleção brasileira de futebol em copas do mundo, símbolos que remetem à pátria, eram invariavelmente lembrados, como bandeiras, estampas e hinos. Capelato afirma que "a bandeira brasileira e a figura de Vargas foram os símbolos mais explorados nas representações visuais do Estado Novo". 45

Não somente nas décadas de 1930 e 1940, mas por toda a extensão do século $X X$, símbolos da pátria permaneceram recorrentemente lembrados em ocasiões de copas do mundo, ou de olimpíadas. Foi (e continua sendo) nestes momentos, que a população brasileira, seguidas vezes, ouvia e visualizava, respectivamente, o hino e a bandeira nacionais, embora este fenômeno não tenha sido restrito ao caso brasileiro. $\mathrm{O}$ nacionalismo se expressava durante as competições em diversas partes do mundo. ${ }^{46}$ Ao conquistar o campeonato mundial em 1958, na Suécia, o sentimento de unidade nacional foi amplamente explorado pelo governo federal.

Ao perceber a interpretação dúbia que cantar e admirar símbolos nacionais poderia ocasionar, o governo federal não hesitou em tirar proveito. Procurou aproximar a paixão popular pelo futebol ao amor à Pátria. Torcer pela equipe de futebol do Brasil, significaria, simbolicamente, lutar pelo progresso do país para além das questões

43 Cf. OLIVEIRA, op. cit., p. 159.

44 Cf. SILVA, op. cit.

45 CAPELATO, Maria Helena Rolim. Multidões em cena: propaganda política no varguismo e no peronismo. Campinas: Papirus, 1998, p. 48.

46 Cf. HOBSBAWN, Eric. Nações e nacionalismos desde 1780. Rio de Janeiro: Paz e Terra, 1990, p. 170. 
esportivas. Consideramos importante apontar para o fato de que, sobretudo, em períodos mais recentes, essa aproximação foi sendo construída pelo poder público, em especial na conquista do tricampeonato mundial pelo Brasil, quando o presidente Emílio Garrastazu Médici explorou a conquista como um das formas de legitimar seu governo durante o período da ditadura militar. ${ }^{47}$

O projeto político e cultural do governo brasileiro nas décadas de 1930 e 1940 esteve amplamente atrelado também, às atividades físicas. Nesse período - sobretudo durante o Estado Novo o poder público passou a assumir algumas das atividades que, até então, diziam respeito tão somente à sociedade civil, mas que depois passaram a ser apropriado pelo Estado. O esporte, e especialmente os esportes de massa, como é o caso do futebol, e todo o universo que o circunda, estiveram a seu serviço.

A instituição do Departamento de Imprensa e Propaganda, que se subordinava diretamente ao Presidente Getúlio Vargas, exerceu papel fundamental na difusão do "consumo" dos elementos culturais do país. Veículos de informação como periódicos e transmissões radiofônicas expressavam suas opiniões, e emitiam as notícias, de forma sempre a enaltecer o regime político implantado, e afirmavam que o "esporte deveria estar a serviço da pátria".

A concepção dos elementos da cultura popular brasileira veiculada pelo DIP, e pelos órgãos a ele subordinados, permitia justificar a plena intervenção do Estado nas suas mais diferentes manifestações artísticas, políticas, culturais e esportivas. A partir disso, é possível supor que a atividade física foi explorada por representantes do governo federal como uma das formas de legitimidade das suas ações durante o regime do Estado Novo, em particular no que concerne às perspectivas de fortalecimento da Nação.

Recebido em 27 de abril de 2007.

47 Cf. SALDANHA, João. Histórias do futebol. Rio de Janeiro: Revan, 1994. Sobre o desencadeamento de posturas como estas do Presidente Emílio Garrastazu Médici, ver ALMEIDA, Maria Hermínia Tavares de. \& WEIS, Luiz. Carro-zero e pau-de-arara: o cotidiano da oposição de classe média ao regime militar. In: SCWARCZ, Lilia Moritz (org.). História da vida privada no Brasil: contrastes da intimidade. São Paulo: Companhia das Letras, 1998 (vol. 4), p. 319-409. 